\title{
LOS MORISCOS ARAGONESES Y SUS LENGUAS
}

Louis Cardaillac*

Braudel en 1949, en su obra La Méditerranée et le monde méditerranéen, insistía ya sobre la gran variedad de las comunidades moriscas en España. Recalcó que no hay un solo problema morisco en España sino varios, según las zonas y las épocas ${ }^{1}$.

Precisamente la lengua es el distintivo más peculiar de cada una de esas comunidades; es la señal de identidad más característica que las define ya que refleja las condiciones históricas, políticas, sociológicas particulares y diferentes en cada una de ellas.

Bernard Vincent expresó este mismo punto de vista en un capítulo de su obra El río morisco que tituló "Reflexión documentada sobre el uso del árabe y de las lenguas románicas en la España de los moriscos". Su estudio se basa esencialmente sobre los granadinos valencianos y navarros. Deliberadamente sólo alude al caso de los aragoneses que voy a desarrollar aquí ${ }^{2}$.

Mi estudio se desarrollará en tres partes: después de presentar a grandes rasgos a esa comunidad, presentaré el uso de las lenguas romances por los aragoneses, o sea el aragonés y el español. Luego analizaré su práctica del árabe, esencialmente escrito, y finalmente estudiaré el caso del aljamiado, el castellano transliterado en caracteres árabes que representa una síntesis de las dos lenguas.

También quiero precisar que varios especialistas que abordaron el estudio de los moriscos aragoneses se interesaron por sus lenguas, pero ninguno de ellos se preocupó por presentar una síntesis y ahondar en el tema. Me refiero a Gregorio Colás Latorre, María Soledad Carrasco Urgoiti, Jacqueline Fournel-Guérin, María José Cervera Fras, Alberto Montaner Frutos, Manuel Lomás Cortés y Bernard Vincent entre ellos. Encontré varias informaciones en sus escritos que aprovecho aquí.

* El Colegio de Jalisco, México.

1. Fernand BRAUDEL, La Méditerranée et le monde méditerranéen á l'époque du Philippe II, París, Armand Colin, 1949, vol. I, p. 49.

2. Bernard VinCENT, El río morisco, Granada, Universidades de Granada, Valencia y Zaragoza, Biblioteca de Estudios Moriscos, 2006, pp. 105-118. 


\section{¿QUIÉNES SON ESTOS MORISCOS ARAGONESES?}

Primero, hay que decir de ellos que representan aproximadamente un $20 \%$ de la población total (mientras que sus vecinos valencianos, más numerosos, llegan a ser la tercera parte). Se calcula que en el momento de la expulsión fueron más de 60.000 en salir de España. Unos 45.000 aproximadamente salieron de Agde y de otros puertos del Mediterráneo y los demás del puerto de los Alfaques, y eso durante el verano de 1610. El 16 de septiembre se daba por concluida la operación, como comunicaron al monarca los responsables del despliegue logístico.

En Agde todos los documentos de los archivos distinguen a los moriscos aragoneses y a los granadinos. Los aragoneses se embarcaron hasta fines de noviembre de 1610, y todo el año de 1611 el tema de los moriscos aragoneses estará de actualidad en Montpellier, ya que varios procesos fueron incoados y ganados por moriscos que habían sido víctimas de patrones de barcos que les habían despojado de sus bienes en el curso de su viaje al exilioº ${ }^{3}$.

Efectivamente, dentro de la población morisca de la Península, el morisco aragonés cobra un marcado carácter de excepcionalidad frente a sus correligionarios valencianos o granadinos más analizados. El aragonés, según varios testimonios contemporáneos, ha perdido, al mismo tiempo que el uso de sus vestidos, el de su lengua. Por ejemplo, Lupercio Leonardo de Argensola escribe: "Hay en Aragón como en otros muchos reinos de España muchos moriscos, aunque [allí] en hábito y en lengua no se diferencian de los otros hombres" ${ }^{\prime 4}$. Y Covarrubias, que publica su diccionario el año mismo de la expulsión, da la definición siguiente de la palabra tagarinos:

"Son los moriscos antiguos criados entre cristianos viejos, en lugares de Castilla y Aragón, los cuales saben igualmente nuestra lengua y la suya, de modo que apenas se pueden distinguir ni conocer, salvo por la orden que con ellos se tiene de que vivan en ciertos barrios".

Cervantes, casi al mismo tiempo, nos dice que en Berbería el término de tagarino se aplica a los moriscos de Aragón y habla de ellos en términos parecidos a los que usó Covarrubias.

Podríamos añadir testimonios inquisitoriales en los que se menciona en diversas ocasiones que esos moriscos aragoneses, según su entorno, hablaban castellano o aragonés. Es notable que el tribunal de Zaragoza no necesitaba intérpretes para interrogar a los reos. Tampoco hubo procesos ni denuncias

3. Sobre este punto se puede consultar Louis CARDAILlAC, Le passage des Morisques en Languedoc, Montpellier, 1970.

4. Lupercio Leonardo de ARGENSOLA, Información de los sucesos del reino de Aragón en los años de 1590 y 1591, en que se advierte los yerros de algunos autores escrita por Lupercio Leonardo de Argensola, Madrid, Imprenta Real, 1808, p. 67 (obra escrita en 1604).

5. Citado por María Soledad CARRAsco Urgoiti, El problema morisco en Aragón al comienzo del reinado de Felipe II, Madrid, Castalia, 1969. 
contra ellos por hablar la lengua árabe. Es evidente que entre ellos usaron en sus aljamas alguna variante del árabe hablado. Sin embargo, no existe un dialecto árabo-aragonés elaborado como hubo un árabe-granadino y otro valenciano. Es cierto que lo que saltaba más a la vista era su asimilación lingüística a su entorno viejo cristiano.

Se decía de ellos que eran "latinados" o sea ladinos, en su primer sentido. También se llegó a decir de ellos que eran "aljamiados" en contraposición con arabizados.

Esta asimilación lingüística a la sociedad veterocristiana tiene varias explicaciones. Primero, la larga convivencia con los cristianos, la cual empezó ya en el siglo XII cuando se registró el más espectacular avance de las tropas cristianas. En aquella época las huestes de Alfonso I rompieron el frente de los almorávides. Los últimos conatos de resistencia armada fueron aniquilados en Cutanda en 1120. El fin del dominio político de los musulmanes provocó el debilitamiento paulatino de las expresiones culturales en lengua árabe ${ }^{6}$.

El mudéjar aragonés poseía su propia cultura islámica y la mantendrá a lo largo de los siglos, aunque en situación de vencido, lo que dificultaba la empresa. Esas poblaciones siempre se consideraron naturales de aquellas tierras en las que muchos tenían sus raíces remotas. De su cultura, similar a la del resto del Islam, van a conservar unos rasgos privativos que mantendrán celosamente bajo el amparo y las garantías de la protección jurídica que les deparaban la Casa aragonesa y los nobles. El mudejarismo, fenómeno típicamente aragonés y que se propagó después con los avances de la Reconquista, tuvo aquí un desarrollo de varios siglos.

Esta convivencia heredada de la Edad Media se acentuó en el siglo XVI con la conversión de los mudéjares en 1526. Así se aumentaba para ellos el peligro de aculturación.

El morisco aragonés es en el siglo XVI en un $90 \%$ un vasallo de señorío laico o eclesiástico y en un 10\% es hombre libre. Es decir, que en su mayoría están metidos en un sistema social en el cual el señor asume la jurisdicción civil y criminal. Controlaba el señor el concejo heredado de la aljama. No sólo el nuevo convertido de moro dependía directamente a través de esa organización social de la nobleza o de la iglesia, sino que estaba vigilado por la red inquisitorial, a la cual están sometidos todos los moriscos, cualquiera que sea su condición social ${ }^{7}$.

Además de este pasado de varios siglos en común, otra circunstancia va a contribuir a dar a las comunidades moriscas aragonesas un rasgo peculiar: su si-

6. Ver sobre este punto la ponencia de María Luisa LEDESMA RUBIO, «Los mudéjares aragoneses: de la convivencia a la ruptura», en Destierros aragoneses I Judios y moriscos, Zaragoza, Institución de Fernando el Católico, 1988, pp. 171-188.

7. Sacamos varias informaciones de Gregorio COLÁs LATORRE, «Los moriscos aragoneses y su expulsión», en Destierros aragoneses..., pp. 189-215. 
tuación geográfica ${ }^{8}$. No hay, contrariamente a Valencia, comarcas enteramente moriscas, sino que, en un mundo dominado por los cristianos viejos, los núcleos conversos están diseminados por todo el territorio con mayor o menor densidad. Cierto, hay algunas zonas en que la proporción de moriscos es particularmente alta, por ejemplo en el valle del Jalón, a lo largo del río Huerva, o en los meandros del Ebro, cerca de Sástago, o en la región de Huesca, al pie de los Pirineos, o en las llanuras de Belchite, también en las estribaciones del Moncayo al norte del Calatayud y en la provincia de Teruel, en su parte norte. En el censo de 1593 de la Inquisición de Zaragoza aparecen 55 pueblos con la mención de "todos moriscos". Pero en otros muchos la población es mixta, con diferencias notables en la proporción de unos y otros.

En las ciudades principales existieron a lo largo del siglo morerías, llamadas después de la conversión barrios de convertidos.

\section{LA PRÁCTICA DE LAS LENGUAS ROMANCES}

En esta diversidad poblacional, las lenguas de los cristianos son prácticamente conocidas por todos, hasta el punto de que nunca los obispos pedirán la ayuda de sacerdotes que conozcan árabe para la evangelización, a la diferencia de Granada y Valencia.

En Aragón se utilizaron dos lenguas romances: el español y el aragonés. La aragonización y la castellanización son un fenómeno generalizado y particularmente manifiesto en las élites que no sólo hablan el castellano o (y) el aragonés sino también lo escriben. Es cierto que aquello denota una progresiva y evidente asimilación a la sociedad cristiana que los envuelve. El fenómeno se produjo progresiva y espontáneamente como producto de la larga convivencia y la inmersión en una sociedad romance hablante.

Del uso del aragonés por los moriscos nos quedan varias pruebas. Se conocen dos obras clandestinas que se escribieron en este dialecto especial de Aragón: el Rekontamiento del libro de Aleixandre y el Poema de alabanza de Mahoma.

Además, es notable que hasta en los escritos castellanos esos moriscos utilizan una lengua plagada de aragonesismos. Pues la literatura aljamiado-morisca es española en su más amplio sentido, y sólo muy limitadamente castellana, ya que la mayor parte de los escritos aljamiados son de origen aragonés. Prácticamente todos los autores de las ediciones de los textos publicados hasta ahora señalan esta influencia del aragonés en la lengua de los moriscos ${ }^{9}$.

8. Escribe Gregorio Colás Latorre: “La distribución geográfica y un pasado de varios siglos en común constituyen dos elementos fundamentales, a la hora de abordar el estudio morisco en Aragón", Ibídem, p. 198.

9. Es el caso de las ediciones de los textos publicados en la colección de los textos publicados en la editorial Gredos bajo la dirección de Álvaro Galmés de Fuentes (CLEAM). 
La castellanización es mucho más importante en la época morisca. En el siglo XVI el castellano ha superado ya al aragonés. En los manuscritos tardíos, todos en castellano, los aragonesismos no son más que esporádicos y se utilizan al mismo tiempo que sus equivalentes castellanos: feyto frente a fecho, konsello frente a konsejo, etc. ${ }^{10}$.

La castellanización denota una progresiva asimilación cultural a la sociedad cristiana que los envuelve. Uno de los refugiados en Túnez, en una de sus obras escritas en el exilio, incluye una novela ejemplar a la española, entreverada de versos de Lope y Garcilaso y otros autores del Siglo de Oro. Manifiesta así una identidad cultural española, adquirida en el suelo de su patria hispánica ${ }^{11}$.

Sobre la asimilación cultural a la sociedad cristiana, Gregorio Colás Latorre cita las representaciones teatrales que se hicieron en varios pueblos moriscos en 1574 del Auto de la destruyción de Troya y de La comedia pastoril de Torcato ${ }^{12}$. La Inquisición supuso que esas obras se compusieron y se representaron para festejar la caída de La Goleta en manos de los moros cinco meses antes. Estas dos obras son la evidencia de la integración lingüística en el mundo cristiano, pero no ideológica. Los moriscos no se niegan a utilizar el castellano para celebrar victorias de sus correligionarios en contra del mundo cristiano. Y estas celebraciones se acompañan de algunas muestras más que indican el alto nivel de su integración en la sociedad de los dominantes. En efecto, la Inquisición escribió a Felipe II que en varias circunstancias celebraron las victorias islámicas sobre los cristianos: "se vistieron como moros y se hizieron juegos de cañas, corrieron toros y otros muchos regozijos". Teatro escrito en castellano, juegos de cañas y corridas de toros representan unos indicios que van en el mismo sentido: nos muestran una fuerte penetración de la civilización dominante ambiental en la vida morisca.

Pero al mismo tiempo que aceptan esta asimilación social y especialmente lingüística, los moriscos afirman su identidad. Admiten este tipo de relaciones como un hecho consumado, irreversible, lo que quiere decir que hacen la parte del fuero.

Esta lengua española, que ya es parte de su identidad adquirida, la van a usar como una herramienta en su defensa. En actitud de resistencia, expresarán en castellano su vivencia del Islam. Se la apropian como vehículo de sus creencias y de sus prácticas islámicas.

10. Véase la ponencia de Gisela LABIB sobre la lengua de los moriscos y el aragonés, «El papel de la literatura aljamiada en la transmisión de algunos aspectos de la lengua árabe sobre el aragonés», Actas del Coloquio internacional sobre la literatura aljamiada y morisca, Madrid, Editorial Gredos, 1978, pp. 337-363.

11. Se analiza otros muchos puntos en común entre obras literarias españolas o europeas y los escritos moriscos en la ponencia de Álvaro GALMÉS DE FUENTES, «El interés literario en los escritos aljamiado-moriscos», Actas del Coloquio internacional..., pp. 189-210.

12. Gregorio COLÁS LATORRE, «Los moriscos aragoneses: una definición más allá de la religión y de la política», Sharq al-Andalus, 12, 1995, pp. 147-168. Las obras de teatro han sido publicadas por Francisco YNDURAIN, Los moriscos y el teatro en Aragón, Zaragoza, Institución “Fernando el Católico", 1986. 
Es de gran interés evocar rápidamente la producción escrita en español de esos moriscos aragoneses y citar algunos de sus autores conocidos.

La temática de estos textos es muy diversa. Primero existió una literatura que podemos llamar de viaje. Se trata de varios itinerarios difundidos por todo Aragón que permiten a los moriscos organizar su huida hacia los países islámicos, antes de la expulsión, unos pasaban por Bearn y otros se dirigían al Mediterráneo ${ }^{13}$. Existe otro texto que evoca la peregrinación de un aragonés a La Meca. Se ha publicado con el título de Las coplas del peregrino de Puey Monçón ${ }^{14}$.

Otra categoría de textos son las profecías llamadas "jofores" o "alguacías" que anunciaban la próxima venida de un libertador y que levantaban el ánimo de los moriscos en los momentos de crisis. Metidos en un ambiente milenarista ponían sus esperanzas en la llegada de un mesías.

También abundan en español, y eso es muy interesante, varias obras de polémica anticristiana. Así, emplear el español no es para ellos ningún compromiso ideológico con la sociedad cristiana vieja, ya que la lengua española viene a ser aquí no sólo una herramienta de defensa sino de ataque.

El ejemplo más ilustrativo que se puede citar es el de Juan Alonso Aragonés, que demuestra en una poesía en versos de romance a la vez su gran cultura hispánica y el grado extremo alcanzado en la polémica anticristiana ${ }^{15}$. El poeta apostrofa a los critianos, preguntándoles cómo pueden afirmar que comen a su Dios con la hostia, cuando todo lo comido ha de someterse inevitablemente a los procesos digestivos. Escribe:
“Bosotros que en una ostia, tenéis por fe que está Dios mirad qué gentil alivio, lo que se come se saca que dezís el sagramento, y os coméis aquel Dios buestro, pues se sabe por muy Zierto por aquel postigo biejo" ${ }^{16}$.

Estamos aquí ante una reinterpretación escatológica y escandalosa del romance épico de Entierro de Fernandarias.

$\mathrm{Y}$ en cuanto a los autores moriscos aragoneses que proclaman su identidad islámica en sus escritos en español, sólo citamos a dos poetas que escribieron en vísperas de la expulsión. El primero de ellos, Muhammad Rabadán, en un largo

13. Estos itinerarios han sido estudiados y publicados por varios autores.

14. La obra ha sido publicada por Mariano de PANo y RuAtA, Las coplas del peregrino de Puey Maçón, viaje a la Meca en el siglo XVI, Zaragoza, Comas Hermanos, 1897.

15. Ms. 9067 de la Biblioteca Nacional de Madrid, $\mathrm{f}^{\mathrm{s}} 205 \mathrm{r}^{\circ}-208 \mathrm{r}^{\mathrm{o}}$. Citado en Louis CARDAILlAC, Morisques et Chritiens, un affrontement polémique 1492-1640, París, Klincksieck, 1977, p. 481.

16. Ver Actas del Coloquio internacional..., pp. 233-234. 
poema exalta "el esclarecido linaje del Profeta y el pueblo árabe", en la introducción nos precisa que redactó su obra para los que pudieran dudar, precisamente a causa del prolongado contacto con los cristianos. Escribe:

“Aunque la fe y creyençia estaba refirmadísima en todo nuestro reino por la graçia de Allah, tahala, siempre las tales cosas entre la gente flaca suelen causar tibieza y escándalo en corazones tan flacos, de amonestación muy limitada y tan inçitados e induçidos y amenazos y prendidos de los bravos alquefirinos [infieles], que sólo en esto ponían su felicidad y gloria"17.

Otro poeta es Muhammad Devera, quien también lamenta la pérdida entre los suyos "del lenguaje arábigo por la grande opresión y apretura que siempre avemos tenido en bivir entre nuestros enemigos"18. Pero al mismo tiempo se muestra comprensivo con esa aceptación de las lenguas romances entre ellos. Una postura que pudo parecer ambigua.

Lo que quiere decir es que entre los moriscos aragoneses no hay ningún Ibn Daúd que se levante para proclamar: "Quien pierde su lengua pierde su ley", como lo hizo precisamente este morisco granadino en el momento de la sublevación de las Alpujarras. Los intelectuales moriscos aragoneses abordan el problema lingüístico con otro sesgo. Para ellos se trata de convertir una derrota lingüística en victoria: a través del castellano se esfuerzan por conservar sus creencias islámicas. En la última parte de este estudio veremos cómo esos moriscos van a ser además autores de un fenómeno creador importante: van a apropiarse de la lengua romance de sus adversarios haciendo de ella una lengua mixta, el aljamiado, que ilustra su personalidad más profunda e íntima. La base será el castellano y la vestidura, el árabe, es un castellano transliterado en caracteres árabes. El aljamiado es un idioma dividido como su propia personalidad compleja. Es a la vez la expresión de una realidad y la de un anhelo, la manifestación de un espíritu de resistencia frente a la degradación cultural impuesta por las circunstancias ${ }^{19}$.

Pero a pesar de todos esos esfuerzos por conservar su identidad islámica, y a pesar de aceptar todas esas asimilaciones culturales, especialmente la lingüística, los moriscos toman conciencia de que, a la larga, todos esos esfuerzos pueden resultar vanos. Los intelectuales se levantan en contra de la pasividad de algunos que se dejan asimilar completamente y de vez en cuando lanzan un grito casi desesperado y de advertencia solemne. Por ejemplo, en el Ms. III de la colección los manuscritos de la Junta, uno de los que fueron encontrados en Almonacid de la Sierra, se encuentra esta amenaza del infierno para los mo-

17. Louis Cardaillac, Morisques et Chrétiens..., pp. 70-71.

18. Ibídem, p. 145.

19. Los estudios sobre el aljamiado abundan. El más reciente estudio publicado es la magnífica síntesis de Luce LóPEz BARALT, La literatura secreta de los últimos musulmanes de España, Madrid, editorial Trotta, 2009. 
riscos que frecuentan demasiado a los cristianos: "El muslim que acompaña con el cristiano cuarenta días por amistad dél, si muere en estos cuarenta días, muere descreyente y va a yahanam"20.

\section{LA LENGUA ÁRABE ESCRITA}

Acabamos de ver cómo esos moriscos, a pesar de haber casi perdido la práctica oral de la lengua árabe y de haberse asimilado lingüísticamente a la sociedad cristiana que les rodea, conservan su fe musulmana. Y para ello cuentan con dos circunstancias favorables.

Primero, su condición de vida: viven en aljamas. La aljama en un sentido etimológico es "la comunidad" en la que habita el mudéjar primero, luego los moriscos. Es el sostén de la comunidad musulmana dentro de la sociedad cristiana. Allí apartado puede emprender un movimiento clandestino de resistencia frente a las presiones cristianas ${ }^{21}$. La institución de la aljama adquirió su carácter definitivo en Aragón en los altos siglos medievales XII y XIII, luego, según el modelo aragonés, se implantará en Valencia, las dos Castillas y Extremadura. En la época de los moriscos, en Aragón se llamará "concejo de cristianos nuevos de moros", conservando su estructura eficaz para mantener la cohesión de la comunidad.

El segundo elemento favorable es la presencia entre los moriscos de alfaquíes $^{22}$. Muchos de ellos fueron llevados a la Inquisición por ser propagandistas del Islam, o sea dogmatizadores. Son los profesionales de la religión, desempeñando un gran papel en toda la vida religiosa y social de la comunidad. Es impresionante el número de alfaquíes condenados por el Santo Oficio: unos vivían en las aljamas y otros son itinerantes, desplazándose a petición de los habitantes. En Aragón aparecen, más que en otras regiones, como el contrapeso del párroco en sus parroquias. De hecho compiten en influencias.

Muchas veces, los alfaquíes se encargan de la instrucción religiosa ya que eran apreciados por su ciencia coránica; la expresión "sabio en la secta" es muy usada en los procesos inquisitoriales. Así en 1588, Alexos Funero, a solicitud del dueño de una casa, enseñó "la zala" y las "azoras de moros" a dos hijos de la familia, copiando con mucho cuidado el texto de las oraciones delante de ellos y enseñándoles a leerlas, "para que aprendiesen mejor las dichas azoras las escribía

20. Ms. III del Instituto Miguel Asín, Madrid, $\mathrm{f}^{\mathrm{o}} 134 \mathrm{r}^{\circ}$.

21. Ver la ponencia de Míkel de EPALZA, «Caracterización del exilio musulmán: la voz de mudéjares y moriscos», Destierros aragoneses..., pp. 221-223. Especialmente el apartado dedicado a la aljama.

22. Sobre el papel de los alfaquíes en las aljamas ver Rafael CARRASCO, Deportados en nombre de Dios, La expulsión de los moriscos: cuarto centenario de una ignominia, Madrid, ediciones Destino, 2009, p. 144 y siguientes. También muchos casos de alfaquíes presentados en Jeanne VIDAL, Quand on brûlait les morisques 1544-1621, Nîmes, Imprimerie Barnier, 1986. 
de su mano en letra moriega en un cuadernico" ${ }^{23}$. En un pueblo apartado aragonés, Jarque, un joven alfaquí de apenas 22 años supo ganarse la confianza de los vecinos: "teniéndolo por buen alfaquí lo llevaron conducido a un lugar de moriscos para que les enseñase la secta y le señalaron salario por ello".

En otra circunstancia, veremos cómo la Inquisición se mostrará preocupada por esta competencia desleal y herética con las autoridades religiosas católicas y dirá de esos alfaquíes: "sabían de cierta ceremonia por las ánimas de los difuntos como los cristianos hacen decir misa" ${ }^{24}$

Los alfaquíes, además, están presentes en las "juntas" que muchas veces se transforman en reuniones políticas en que su parecer es siempre muy respetado. Son los portavoces de un Islam ofensivo. En esas reuniones animan a sus correligionarios a mostrarse firmes y riñen a las personas que se apartan de las prácticas del Islam. Es el caso de Lope Zapatero, "que persuadía a los testigos hiciesen ceremonias de moros y viviesen en observancia de la secta de Mahoma porque de otra manera no se podían salvar" 25 .

Y todos esos alfaquíes saben el árabe coránico. Una de sus misiones es, como lo hemos visto en el caso de Alexo Funeros, difundir gracias a sus conocimientos lingüísticos del árabe escrito el Islam. Los inquisidores son conscientes de que son ellos los que dificultan al extremo los intentos de la Iglesia para borrar entre los moriscos las huellas del Islam. Los inquisidores de Zaragoza en 1579 mandan una carta al inquisidor general en la que escribían:

"Hemos dado cuenta a vuestra señoría de quán al descubierto viven estos convertidos de la secta de Mahoma y de los libros que tienen por enseñarla y sospechas grandes de que tratan con otros moriscos y aún con los de Argel; y el remedio que parece más conveniente es prender a los alfaquíes y principales dellos".

Estas frases son muy claras: esos moriscos aragoneses, más apartados que los valencianos del Maghreb, hacen todos sus esfuerzos por no perder el contacto con el Islam a través de esos textos árabes. Y esos textos son de dos clases principales: primero el Corán, que es el texto básico, y segundo las vidas genealógicas y alabanzas del Profeta Muhammad que fue su transmisor. Y son tan numerosos y están tan difundidos que Jacqueline Fournel-Guérin les dedicó un artículo muy bien documentado ${ }^{26}$.

El árabe escrito ocupa en la escala lingüística el lugar más alto por ser precisamente la lengua del libro revelado. Son una minoría los que lo saben leer y

23. Citado por Jeanne VIDAL, op. cit., p. 41.

24. Ibídem, p. 41.

25. Ibídem, p. 42.

26. Jacqueline FOURNEL-GÚ́RIN, «Le livre et la civilisation écrite dans la communauté morisque aragonaise, 1540-1620», Mélanges de la Casa de Velázquez, Madrid, t. XV, 1979, pp. 241-259. También de la misma autora: Les morisques aragonais et l'Inquisition de Saragosse (1540-1620), Tesis de tercer ciclo, Montpellier, 1980. Esta es una obra fundamental sobre moriscos aragoneses. 
un número todavía más reducido los que lo entienden. Y aunque sea sólo una lengua escrita no es una lengua muerta, sino fuente de vida para todos ellos.

Es impresionante el número de coranes que circulan. Las familias ricas poseen varios, Juan Compañero, por ejemplo, que vive en Zaragoza, posee en su casa unos treinta ${ }^{27}$. Los hay de todos los tamaños: según la Inquisición unos son grandes como un misal, mientras que otros son como un breviario. Otros pequeñitos se pueden llevar en el bolsillo, se les denomina cuartas de Alcorán. Existen redes de productores, iluminadores, copistas, encuadernadores, vendedores y compradores. Numerosos talleres de copistas fueron descubiertos a lo largo del siglo del XVI en Calanda, Codo, Aranda, Trazmos, Ambel, Almonacid de la Sierra, Cuchillos, Brea...

No es que la gente lo entienda. Varios de los poseedores ni saben leer pero para todos ellos es la expresión salvífica de la palabra divina. En las familias se hace un gran esfuerzo para aprender a leer el árabe. En varios pueblos se señala la presencia de varias personas que son "preceptores y enseñadores" de muchachos moriscos. En los procesos se mencionan varias escuelas coránicas clandestinas a cargo de alfaquíes o el papel del padre que enseña a sus hijos a leer el Corán.

Pero hay una gran diferencia entre leer el Corán y entender lo que se lee. Para facilitar su comprensión, los aragoneses imaginan una solución lingüística que les es propia: publicaron coranes bilingües ${ }^{28}$. En una línea escribían el texto árabe y en la otra su traducción al español. Estos coranes árabes de versión española interlineal fueron en Aragón preferidos a los coranes propiamente aljamiados, es decir escritos en español transcrito con caracteres árabes.

Y así el Corán constituye la base de esa literatura árabe aragonesa hasta el punto de ser la obra más copiada y comentada por los moriscos.

Los demás textos aragoneses escritos en árabe que fueron encontrados en Aragón son por lo esencial textos de polémica, heredados de los mudéjares, que sirvieron de base a la polémica anticristiana. Señalamos los más importantes.

Entre las obras en árabe más poseídas está el Kitāb al-šifā... El libro del remedio para la enseñanza de los derechos del enviado de Dios cuyo autor es Qāḍi 'Iyāạ. Es el autor más leído por los moriscos y el más citado, especialmente por Bejarano, Aḥmad al-Hanafī y Juan Alonso Aragonés y el autor del manuscrito 9650 de la Biblioteca Nacional de Madrid. Todos utilizan y desarrollan el gran argumento del Qāḍī 'Tyāḍ: Mahoma es el sello de los profetas y su venida estaba ya anunciada en las escrituras judías y cristianas $^{29}$.

27. Sacamos estas informaciones de Jacqueline FOURNEL-GuÉRIN, «L'Inquisition de Seragosse», en Les morisques et l'Inquisition (bajo la dirección de Louis Cardaillac), París, Publisud, 1990, pp. 171-187.

28. Sobre estos coranes bilingües: Juan VERNET, «La exégesis musulmana tradicional en los coranes aljamiados», Actas del Coloquio internacional..., pp. 123-146.

29. Ver Louis CARDAILlaC, Moriscos y cristianos..., pp. 199-200. 
También se encontró entre los manuscritos de la librería morisca de Almonacid un resumen de la obra del gran polemista oriental al-Gazāli, autor de Al-rad al-ŷamil, Refutación excelente de la divinidad de Jesucristo según los evangelios $^{30}$. Los moriscos muchas veces citan esta obra. Se sabe que la copia de Almonacid fue realizada en la madrasa del arrabal de los musulmanes de Zaragoza en tiempos mudéjares.

\section{LA LENGUA ALJAMIADA}

En la óptica morisca existen dos expresiones lingüísticas: la ${ }^{c} a r a b \bar{y} y a$ y la 'ă̆amìya, palabras que se transcriben en español como la algarabía y la aljamía. La algarabía, según los especialistas, no es la lengua árabe clásica, sino un sistema "en el que se encuentran numerosas faltas ortográficas y gramaticales" por la distancia y separación de las fuentes del arabismo. En cuanto a la aljamía, el término, de origen árabe, designa cualquier lengua no árabe, "aquí se trata del castellano-aragonés de los moriscos, pero puede referirse a cualquier idioma que no sea el árabe, como el persa o el turco". Esta aljamía hablada por los moriscos es muy marcada en Aragón por quienes la hablan: el castellano de los moriscos incluye muchos arabismos y aragonesismos.

Pero con el tiempo las palabras aljamía y aljamiado evolucionaron. Concretamente el aljamiado designa la forma de civilización escrita, característica de los moriscos aragoneses (y luego de los castellanos). Estos textos forman la literatura aljamiada. A través del castellano van a conservar sus creencias islámicas. Pero, al mismo tiempo, utilizan la grafía árabe al transcribir la lengua romance que hablaban. La conservación de los signos del alifato era el último vestigio de su cultura islámica que mantenían en secreto. Esta escritura representaba el lazo de unión que entre ellos mantenían y que, a su vez, les vinculaba con su propia comunidad islámica.

Muchos de sus manuscritos se han descubierto después de la expulsión de los moriscos, en los escondrijos donde los habían abandonado los moriscos. El mayor hallazgo fue el que se dio en Almonacid de la Sierra y que consta de unos 400 volúmenes: parece que era el fondo de un almacén de un librero morisco. Otros hallazgos se dieron en varios lugares, especialmente en Belchite. Varios proceden de las comunidades moriscas que se asentaban en las riberas del río Ebro y en los valles de sus afluentes de la margen derecha: Queiles, Huerva, Martín y Jalón entre otros.

Los moriscos se apropiaron de la lengua romance de sus adversarios y a través de ella crearon una importante corriente al aceptar escribir en una lengua no árabe, especialmente de temas religiosos islámicos.

30. Ibídem, pp. 196-198. 
Esta lengua la hicieron suya: no sólo la vistieron con un disfraz árabe, escribiéndola con los caracteres del alifato árabe, sino que dieron un paso más. A través de ella se esforzaron por recrear unas estructuras de frase que se acercan al árabe escrito, y también utilizaron unos giros gramaticales arabizados y unos "calcos semánticos" que les permitían acercar su vocabulario a los conceptos coránicos $^{31}$. Con todos esos trasvases al castellano y aragonés crean en cierta manera una lengua nueva. Fue, ni más ni menos, una manera de islamizar el castellano. En este sentido se habla de la hibridez de los textos aljamiados moriscos.

Míkel de Epalza en un artículo clarificador interpreta esta evolución de la situación de aculturación de los aragoneses no como una señal de derrota sino, paradójicamente, "como un signo de fuerza y confianza en sí misma de la cultura islámica de los musulmanes" ${ }^{\prime 2}$. El mismo autor escribe también: "Intentaron islamizar el castellano, insertar el islam en la sociedad cristiana hispánica". Este fenómeno no se dio en Murcia ni en Extremadura ni en las regiones catalanohablantes de Cataluña y Valencia. Es curioso constatar que el área del aljamiado coincide con el área del arte mudéjar. Estos dos fenómenos son expresiones parecidas de esa convivencia secular de dos civilizaciones que llegó a cierto sincretismo.

Esta situación particular de los moriscos aragoneses, lingüísticamente asimilados a los cristianos, no dejó de alimentar las fobias de los cristianos viejos y de la Inquisición. Estos moriscos tan parecidos al resto de la población en sus trajes y lenguas llegaban a ser indistinguibles y por lo tanto más peligrosos, ya que podrían así disimular el peligro que representaban. El riesgo era de desintegración de la sociedad desde el interior, y lo que temía la inquisición es precisamente que intentaran islamizar desde dentro a la sociedad cristiana vieja aragonesa. El mismo temor que se tuvo en Andalucía cuando unas generaciones antes se creó la Inquisición en Sevilla contra una comunidad perfectamente asimilada culturalmente a la sociedad veterocristiana, la de los conversos judíos. En Aragón cada vez que se descubría un caso que podía fomentar este miedo, la Inquisición actuaba con mucho rigor. Citemos algunos de esos casos que muestran que la Inquisición pretende oponerse al Islam militante y organizado que, según ella, estaba ganando terreno en las fuerzas vivas del catolicismo, es decir, hasta en el mismo clero.

El aislamiento geográfico de muchos pueblos aragoneses, lejos de carreteras fácilmente transitables, facilitaba la cohesión del grupo morisco que los poblaba. En ellos el cura llegaba a declararse impotente. Es el caso de Gea de Albarracín, situado en el límite noroeste de la Inquisición valenciana. Allí los moriscos son "tan moros como los de Argel". Mosén Lorenzo Lope, que era el párroco desde hacía más de doce años, tenía que aceptar, por ejemplo, que enterrasen a

31. Reinhold Kontzi, «Calcos semánticos en textos aljamiados», en Actas del Coloquio internacional..., pp. 315-336.

32. Míkel de Epalza, op. cit., pp. 223-227. 
los muertos "en tierra virgen, que si no lo hiciera, entendiera que le habrán de matar". También les permite la práctica del ayuno de Ramadán y los absuelve fácilmente de sus pecados de infidelidad recibiendo de ellos algunos regalos a cambio: "la absolución en sí la da condicionalmente; todos los delitos de aquella gente se resuelven en una carga de leñas"33. A descarga suya hay que decir que los párrocos de los pueblos moriscos varias veces fueron maltratados por sus fieles, sobre todo cuando hay sospecha de que los haya denunciado a la Inquisición; así el cura de Brea fue asesinado en 1608. Se le acusó de ayudar a su hermano, familiar del Tribunal y de ser autor de muchas denuncias.

Peor todavía, una larga serie de curas fueron acusados de ser cómplices del Islam y de situarse en el otro campo. Veamos algunos $\operatorname{casos}^{34}$ : mosén Domingo Pérez, cura de Rueda de Jalón, tiene una compañera morisca con quien comparte su vida. Reza las oraciones coránicas y degüella las aves destinadas a su consumo invocando a Allah. Además cubrió los muros de su iglesia con escritura árabe. En Calanda, mosén Juan Lozano anima a sus parroquianos a que no denuncien a los moriscos. En la iglesia de Santa María de Zaragoza, uno de los vicarios es morisco, vive maritalmente con una morisca que le dio seis hijos. En 1610 se le acusa de practicar el Islam. El caso más curioso es el del cura de Rodén, que todos consideran como un buen musulmán por su obediencia a las prácticas religiosas islámicas. En Cuaresma, dice de todos sus fieles que hay constancia de haberse confesado sin ni siquiera oírlos, hasta que, conociendo su benevolencia, muchos moriscos acuden de los pueblos vecinos a pedirle el mismo favor. En 1610 se le condenará a la abjuración, dos años de reclusión en un monasterio y cuatro años de suspensión de su ministerio.

A partir de 1560, la Inquisición aragonesa se hizo todavía más represiva. Es notable que el tribunal de Zaragoza, junto con el de Valencia, fue uno de los dos más severos de la Península. Entre los dos juzgarán la mitad de los moriscos condenados en España: 2.371 para Zaragoza y 2.465 para Valencia, o sea $60 \%$ y $73 \%$ respectivamente del total de encausados por ambos tribunales. Hasta en su forma más dura de la represión, Zaragoza se lleva la palma: en Aragón, un centenar de moriscos fueron quemados en la hoguera (4,2\% de los condenados) mientras que en Valencia representan el 1,3\%, es decir 30 personas ${ }^{35}$.

Así pues la Inquisición quiso combatir lo que consideraba como un intento de reconquista espiritual; se trataba de contrarrestar a toda fuerza ese Islam aragonés que por tal podía amenazar la unidad religiosa del reino.

Otro aspecto que preocupó también a los inquisidores a lo largo del siglo XVI, pero sobre todo a partir de 1568, fecha de la sublevación morisca de las Alpujarras, fue el aspecto político del problema morisco. A partir de ese momento los objeti-

33. Citado por Jeanne VIDAL, op. cit., pp. 64-65.

34. Sacamos estas informaciones de Jacqueline FOURNEL-GUÉRIN, «L'Inquisition de Seragosse...», p. 180.

35. Sacamos estas cifras de Jeanne VIDAL, op. cit., pp. 170-173. 
vos religiosos y políticos del tribunal se confunden. En Aragón -así como en Valencia-los jefes religiosos de las aljamas desempeñan un papel político. A través de ellos se establecen contactos con protestantes de Navarra o turcos del Maghreb. La Inquisición se entera de que algunos de esos moriscos pretenden suscitar una sublevación comparable a la de las Alpujarras y que acumulan armas. En tres ocasiones, en vano, se intentará desarmarlos. Ya en los procesos las palabras "reo" y "junta" serán substituidas por las de "delincuente" y "complicidad".

El periodo de mayor actividad antimorisca por parte de la Inquisición se sitúa entre 1576 y 1593. Corresponde a un progreso acentuado otomano en el Mediterráneo $^{36}$. El poder político se siente amenazado y la Inquisición lo apoya persiguiendo cualquier intento de sublevación o de conspiración, verdadero o supuesto. La Inquisición procura descubrir los preparativos de alianzas con los turcos y llega a detener a varios moriscos que se cartean con Constantinopla o Túnez ${ }^{37}$.

Todo ello significa que los moriscos, a los ojos del poder y de la Inquisición, representan un gran peligro. Para esas distintas instituciones, su asimilación a los cristianos viejos no es más que fachada, ya que fundamentalmente pertenecen al campo de los enemigos de España. Piensan que amenazan su territorio por estar en connivencia con los enemigos exteriores, y por ser unos militantes agresivos del Islam.

Todas esas fobias irán creciendo en la primera década del siglo XVII y contribuirán a la toma de decisión de la expulsión. Rafael Carrasco analiza perfectamente en su libro Deportados en nombre de Dios, el entramado de esas conspiraciones subrayando que:

“tal actitud correspondía a un claro endurecimiento de la práctica inquisitorial contra moriscos que muchos especialistas ya han subrayado. En realidad, la Inquisición tomó el pretexto de la supuesta conspiración para asestar un gran golpe en la cabeza de aquella sociedad morisca que soñaba con desbaratar desde hacía tiempo" ${ }^{\prime 38}$.

\section{CONCLUSIÓN: LAS LENGUAS DE LOS MORISCOS ARAGONESES DESPUÉS DE LA EXPULSIÓN}

Los expulsados del Maghreb, especialmente en Túnez, tuvieron tendencia a formar grupos, como si fueran la perpetuación de las aljamas, agrupándose cada vez que les era posible según su origen. Para aragoneses y castellanos la lengua

\footnotetext{
36. Ibídem, p. 143.

37. Ibídem, pp. 54-61.

38. Ver especialmente el capítulo de Rafael CARRASCO, «La gran conspiración morisca y la desunión de las aljamas», en Deportados en nombre..., pp. 154-191.
} 
castellana siguió siendo un elemento de su identidad, por lo menos para las primeras generaciones. La práctica del castellano perduró hasta el siglo XVIII en algunos pueblos tunecinos, como lo señalan varios viajeros. Por ejemplo, Peyssonnel en su obra Récit d'un voyage sur les côtes de Barbarie declara que en aquella época casi todos los habitantes de origen morisco hablaban todavía español ${ }^{39}$.

Progresivamente se asimilaron lingüísticamente a la población local, practicando en su vida cotidiana el árabe tunecino. En cuanto al árabe coránico y a la lengua escrita los tuvieron que aprender. Nos quedan varios abecedarios y libros de aprendizaje del árabe que fueron escritos para ellos ${ }^{40}$. Se sabe que, en un principio, el piadoso Abū al-Gayt acogió a los moriscos por razones religiosas y humanitarias y les permitió que se instruyeran en la fe musulmana en su propia lengua castellana.

Además, estaba vigente en Túnez y otros países de la orilla del Mediterráneo una lengua oral que el carácter cosmopolita de la población y las necesidades de la comunicación impusieron. Esta lengua es un sabir -en realidad una mezcla de lenguas- que utilizaban mercaderes, cautivos, turcos, árabes y renegados de distintas nacionalidades para intercambiar. Es la famosa lingua franca que conocemos mejor ahora gracias a valiosos estudios recientes de Míkel de Epalza $^{41}$ y de Jocelyne Dakhlia ${ }^{42}$. Esta última investigadora aporta algún que otro testimonio acerca del uso de la lingua franca por los moriscos exiliados - ¿serán aragoneses?-. Cita al padre Antoine Quartier que escribe hacia 1660 en las memorias de su cautiverio que encontró a un morisco y a su familia en la región de Mesrata, al este de Trípoli; con ellos el padre pudo hablar en esta lengua franca y el morisco a su vez le contó que después de vivir en Túnez algún tiempo se estableció en esta región poco controlada por los turcos ${ }^{43}$.

Así fue la epopeya de la comunidad morisca de Aragón vista a través de su lengua. No cabe duda de que el fenómeno lingüístico la distingue de los demás núcleos poblacionales moriscos de la Península.

39. Citado por Jaime Oliver Asín, «Un morisco de Tunis, admirateur de Lope: Étude du Ms S2 de la collection de Gayangos», en Míkel de Epalza y Ramón Petit, Études sur les moriscos andalous en Tunisie, Madrid, Instituto General de Relaciones Culturales, 1973, p. 209.

40. Varios de esos manuscritos fueron comprados en Túnez por el arabista Gayangos en el siglo XIX y están hoy en la Biblioteca Nacional de Madrid.

41. Míkel de EPALZA, «La naturaleza de la lengua franca de Argel y Cervantes», en Cervantes entre las dos orillas, Alicante, Universidad de Alicante, edición de María Jesús Rubiera Mata, 2006, pp. 85-116. Ha aparecido en Valencia, después de entregar el texto de este artículo, el libro póstumo que Míkel de Epalza escribió en colaboración con Abdel-Hakim Slama-Gafsi, El español hablado en Túnez por los moriscos y sus descendientes andalusies (siglos XVII y XVIII). Material léxico y onomástico documentado, siglos XVIII-XX, Valencia, Universitat de Valencia, 2010 (Biblioteca de Estudios Moriscos, n. ${ }^{\circ}$ 6).

42. Jocelyne DAKHLIA, Lingua franca, une langue métisse en Méditerranée, Arles, Actes Sud, 2008.

43. Id., «La langue franque méditerranéenne: assymétrie de la frontiére et illusion du creuset», Cahiers du Centre de Recherches Historiques, Paris, EHESS, n. ${ }^{\circ}$ 42, 2008, pp. 143-144. 


\section{RESUMEN}

Caracterización lingüística de la comunidad morisca aragonesa como comunidad hispanohablante pero que sigue conservando unas relaciones especiales con el árabe como lengua sagrada. El recurso a lo aljamiado es prueba tanto de la cohesión social de esta comunidad, como de su resistencia a la aculturación provocada por su situación de minoría, simbolizada también en el activo papel de sus alfaquíes.

Palabras clave: moriscos, Aragón, aljamiado, español, árabe.

\section{ABSTRACT}

Linguistic characterization of the Aragonese Morisco community as Spanish-speaking community but still retaining a special relationship with Arabic as Sacred Language. Recourse to aljamiado is a proof of both the social cohesion of this community, and its resistance to acculturation caused by their minority status. This resistance is also symbolized by the active role of the fuqah ${ }^{a \prime}$.

Key words: Moriscos, Aragón, aljamiado, Spanish, Arabic. 